\title{
HEMÓLISE DE ERITRÓCITOS EM DISPOSITIVOS DE INFUSÃO INTRAVENOSA: REVISÃO INTEGRATIVA DA LITERATURA
}

Larissa Perez Pardo', Denise Miyuki Kusahara², Maria Angélica Sorgini Peterlini', Ariane Ferreira MachadoAvelar', Mavilde da Luz Gonçalves Pedreira ${ }^{3}$

${ }^{1}$ Enfermeira. Universidade Federal de São Paulo. São Paulo-SP-Brasil.

${ }^{2}$ Enfermeira. Doutora em Ciências. Universidade Federal de São Paulo. São Paulo-SP-Brasil.

${ }^{3}$ Enfermeira. Doutora em Enfermagem. Professora da Universidade Federal de São Paulo. São Paulo-SP-Brasil.

RESUMO: Hemólise extracorpórea pode ser identificada durante processos hemoterápicos. O enfermeiro é um dos profissionais responsáveis pela administração de hemocomponentes e controle de possíveis riscos, portanto deve apropriar-se de conhecimentos que respaldem a prática clínica. O objetivo foi identificar na literatura aspectos relacionados à hemólise em concentrados de hemácias decorrentes de administração de sangue por dispositivos de infusão intravenosa. Realizou-se Revisão Integrativa da Literatura. Incluídos artigos na língua inglesa, espanhola e portuguesa, sem delimitação da data, indexados em quatro bases de dados. Foram selecionadas $12(100,0 \%)$ produções científicas, sendo que em sete (58,3\%) foram analisadas bombas de infusão, em duas (16,7\%) a manipulação de eritrócitos, em duas (16,7\%) a hemólise com combinações de dispositivos e em uma (8,3\%) cateter intravenoso. Os resultados de quatro (33,3\%) destes estudos evidenciaram ocorrência de hemólise. Os estudos apontaram que pode ocorrer hemólise durante a passagem do componente por bombas de infusão e cateteres. DESCRITORES: Segurança do paciente; Transfusão; Hemólise; Eritrócitos; Infusões intravenosas.

\section{HEMOLYSIS OF ERYTHROCYTES IN INTRAVE- NOUS INFUSION DEVICES: AN INTEGRATIVE REVIEW OF THE LITERATURE}

\begin{abstract}
Extracorporeal hemolysis may be identified during hemotherapy. The nurse is one of the professionals responsible for the administration of blood components and the control of possible risks, and must therefore acquire the knowledge which supports clinical practice. The objective was to identify, in the literature, aspects related to hemolysis in concentrates of red blood cells resulting from the administration of blood through intravenous infusion devices. An Integrative Review of the Literature was undertaken, including articles in the English, Spanish and Portuguese languages, without limitation of data, indexed in four databases. A total of 12 (100.0\%) scientific productions were selected, of which seven (58.3\%) analyzed infusion pumps, two $(16.7 \%)$ the handling of erythrocytes, two $(16.7 \%)$ hemolysis with combinations of devices, and one $(8.3 \%)$, the intravenous catheter. The results of four $(33.3 \%)$ of these studies evidenced the occurrence of hemolysis. The studies indicated that hemolysis can occur during the passage of the component through infusion pumps and catheters. DESCRIPTORS: Patient safety; Transfusion; Hemolysis; Erythrocytes; Intravenous infusions.
\end{abstract}

\section{HEMOLISIS DE ERITROCITOS EN DISPOSITIVOS DE INFUSIÓN: REVISIÓN INTEGRATIVA DE LA LITERATURA}

RESUMEN: Hemolisis extracorpórea puede ser identificada durante procesos hemoterápicos. El enfermero es uno de los profesionales responsables por la administración de hemocomponentes y control de posibles riesgos, por lo tanto debe apropriarse de conocimientos para garantizar la práctica clínica. El objetivo fue identificar en la literatura aspectos de la hemolisis en concentrados de hematíes decurrentes de administración de sangre por dispositivos de infusión intravenosa. Fue realizada revisión integrativa de la literatura. Se utilizaron artículos en lengua inglesa, española y portuguesa, sin delimitación de fecha, indexados en cuatro bases de datos. Fueron seleccionadas $12(100,0 \%)$ producciones científicas, siendo que en siete $(58,3 \%)$ fueron analizadas bombas de infusión, en dos (16,7\%) la manipulación de eritrocitos, en dos $(16,7 \%)$ la hemolisis con combinaciones de dispositivos y en una $(8,3 \%)$ catéter intravenoso. Los resultados de cuatro (33,3\%) de estos estudios evidenciaron ocurrencia de hemolisis. Los estudios apuntaron que puede ocurrir hemolisis durante la pasaje del componente por bombas de infusión y catéteres. DESCRIPTORES: Seguridad del paciente; Transfusión; Hemolisis; Eritrocitos; Infusiones intravenosas.

Universidade Federal de São Paulo

Rua José Mauro Lacava, 100 - 09360-390 - Mauá-SP-Brasil

E-mail: larissappardo@hotmail.com 


\section{INTRODUÇÃO}

A história da hemoterapia é dividida em duas fases: empírica e científica. Na era empírica, que se estendeu até século XIX, ocorriam transfusões de animais para seres humanos e entre humanos, sendo que quase todas estas tentativas terminavam em insucesso e morte dos indivíduos receptores e também de alguns doadores. A era científica, a partir do século XX, é iniciada pelas descobertas de Karl Landsteiner quanto à existência de grupos sanguíneos e mais tarde, em 1940, quando descreve o Fator Rh. Essas duas descobertas foram fundamentais no conceito de compatibilidade entre doadores e receptores $^{(1)}$.

A hemoterapia moderna trouxe a ideia de transfundir no paciente, componentes específicos do sangue ou apenas os que o mesmo necessita, por meio de achados de dados clínicos e laboratoriais, opondo-se assim ao uso do sangue total. O concentrado de hemácias, obtido após a centrifugação e extração de plasma de uma unidade de sangue total, é o hemocomponente mais utilizado na prática clínica e tem como objetivo aumentar a capacidade de carreamento de oxigênio e o volume eritrocitário em pacientes com anemia sintomática, sendo bastante útil para casos de anemias e hemorragias agudas ${ }^{(2)}$.

A hemácia tem a função básica e vital de transportar o oxigênio pelo organismo, por meio da hemoglobina. Além das enzimas já citadas, as hemácias possuem a anidrase carbônica, essencial no carreamento do dióxido de carbono até os pulmões para sua eliminação, graças às ligações químicas entre a água e o dióxido de carbono. A hemoglobina funciona ainda como sistema tampão, na manutenção do equilíbrio acidobásico do organismo ${ }^{(3)}$.

Durante os processos hemoterápicos pode ocorrer hemólise extracorpórea. Essa ocorre, principalmente, durante a estocagem do concentrado de hemácias ou por trauma mecânico durante a transfusão ${ }^{(4)}$.

A lesão da membrana das hemácias causa a liberação de hemoglobina no plasma, além disso, uma alta carga de potássio livre é liberada. Caso a hemoglobina livre atinja níveis de 100 mg/dL no plasma, ocorre eliminação através do sistema urinário, muitas vezes, causando hemoglobinúria, tendo como possível efeito final a lesão renal, podendo evoluir para insuficiência renal aguda. Ademais a liberação de potássio pode levar a parada cardíaca e morte, uma vez que este íon livre no plasma, em altas concentrações, altera os impulsos elétricos cardíacos e modifica seu ritmo $^{(3)}$.

A administração da hemoterapia, na maior parte das instituições, é de responsabilidade do enfermeiro e esta atuação está normatizada na resolução COFEN no 306/2006 ${ }^{(5)}$.

Para os procedimentos de transfusão utiliza-se de uma série de acessórios de infusão intravenosa, os quais representam grupo de materiais bastante diversificado em qualidade, preço, apresentação e recomendação de uso.

Eventos adversos podem ser identificados durante a administração de hemocomponentes, comprometendo a segurança do paciente, sendo o controle de tais eventos tema cada vez mais abordado na área da saúde. A segurança do paciente pode ser definida como uma assistência à saúde livre de danos, realizada de maneira certa, no momento apropriado, de modo equânime e eficaz, fundamentado em conhecimento científico e tendo como meta atender as necessidades integrais e individuais do paciente e família.

A prática transfusional é um processo crítico que deve ser realizado com cuidados que promovam a prevenção de infecção, identificação correta do paciente, escolha correta dos acessórios e dispositivos da terapia transfusional, controle da infusão e dos sinais clínicos do paciente que possam indicar, precocemente, a ocorrência de eventos adversos. Porém, além desses cuidados, deve-se garantir que o produto utilizado tenha qualidade e seja benéfico ao tratamento do paciente. Nesse contexto, ressaltase a importância da prevenção da ocorrência de hemólise extracorpórea durante a manipulação ou infusão do hemocomponente ${ }^{(6)}$.

A fim de fornecer subsídios para a realização de pesquisa experimental sobre a temática realizou-se revisão integrativa da literatura, para identificar estudos produzidos acerca da administração de hemocomponentes. Deste modo, o objetivo foi identificar na literatura aspectos relacionados à hemólise decorrente de transfusão de sangue com dispositivos de infusão intravenosa. 


\section{MÉTODO}

O tipo de estudo selecionado foi uma revisão integrativa da literatura. Foram utilizadas seis etapas da revisão integrativa da literatura( ${ }^{(7)}$ : 1) Identificação do tema e seleção da hipótese ou questão de pesquisa; 2) Estabelecimento de critérios para inclusão e exclusão de estudos/ amostragem ou busca na literatura; 3) Definição das informações a serem extraídas dos estudos selecionados/ categorização dos estudos; 4) Avaliação dos estudos incluídos na revisão integrativa; 5) Interpretação dos resultados; 6) Apresentação da revisão/síntese do conhecimento.

As bases de dados utilizadas foram: Scientific Electronic Library Online (SCIELO), U.S. National Library of Medicine (PUBMED), Medical Literature Analysis and Retrieval System Online (MEDLINE) e The Cochrane Library (Cochrane).

Para realizar a busca das produções científicas foram utilizados os seguintes descritores em inglês nas quatro bases: hemolysis, blood cell, infusion devices, transfusion, intravenous infusion devices, red blood cell. Foram utilizados os seguintes descritores também em português na base SCIELO: hemólise, eritrócitos, infusões intravenosas e transfusão de sangue. Na seleção das produções os critérios de inclusão foram: produções em língua inglesa, portuguesa e espanhola, não sendo delimitada data de publicação. A identificação da pertinência do trabalho à resposta do problema de pesquisa deu-se por meio da leitura de títulos e resumos dos estudos.

Foram utilizados três critérios de inclusão: primeiramente considerou-se o idioma dos artigos (inglês, português e espanhol); posteriormente, foi realizada a seleção a partir do título e/ou resumo, respondendo a adequação do tema de interesse, e por último os estudos foram avaliados por meio da análise de conteúdo. As publicações que não estavam alinhadas aos critérios de inclusão foram excluídas.

No total, obteve-se 12 produções científicas incluídas na revisão. Os resultados são apresentados em forma de quadro contendo uma síntese das informações extraídos dos artigos. A Figura 1 demonstra como se deu a seleção dos artigos em cada base.

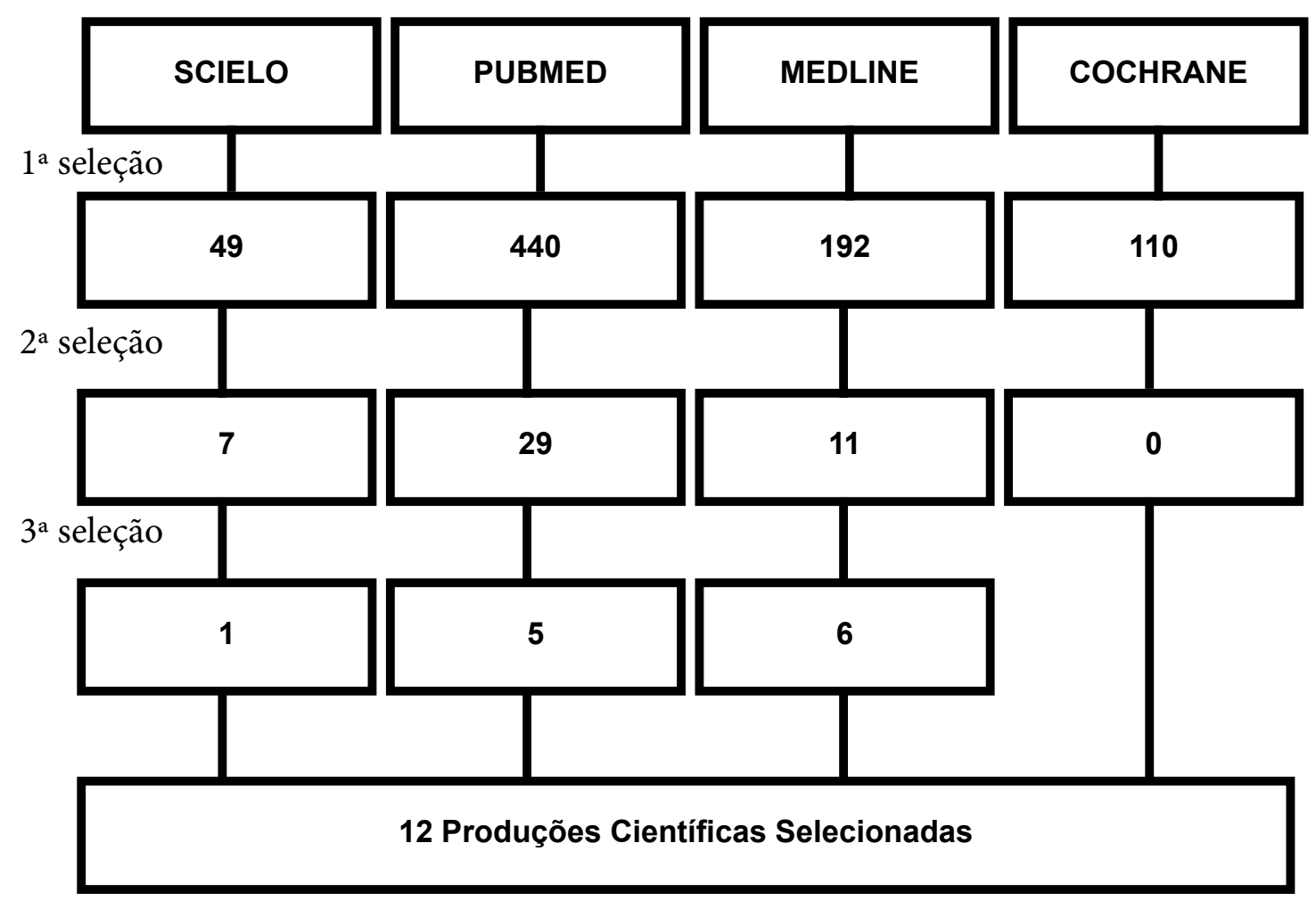

Figura 1 - Fluxograma de seleção dos artigos por base de dado. $1^{\mathrm{a}}$ seleção: pesquisa por descritores; $2^{\mathrm{a}}$ seleção: leitura de títulos e resumos e $3^{a}$ seleção: leitura do artigo na íntegra. 


\section{RESULTADOS}

Por meio da metodologia empregada para a revisão de literatura foram selecionados 12 artigos, sendo 11 (91,6\%) de literatura estrangeira e uma $(8,4 \%)$ nacional, dentre eles seis $(50,0 \%)$ foram produzidos nos Estados Unidos (EUA), uma $(8,4 \%)$ no Brasil, uma $(8,4 \%)$ na Holanda, uma $(8,4 \%)$ na Dinamarca, uma $(8,4 \%)$ na Suíça, uma $(8,4 \%)$ em Israel e uma $(8,4 \%)$ na Inglaterra. Dentre os estudos selecionados para esta revisão, o mais antigo data do ano de 1984 e o mais recente em 2012 como podem ver na Figura 2.

No Quadro 1 pode ser observada síntese dos artigos selecionados para o estudo, apresentados por ordem cronológica crescente de publicação.

Quadro 1 - Resumo dos Artigos Selecionados.

\begin{tabular}{|c|c|c|c|}
\hline Autores/Local & Metodologia/Objetivo & Intervenções & Resultados/Conclusão \\
\hline $\begin{array}{l}\text { Gibson, JS } \\
\text { Leff, RD } \\
\text { Roberts, RJ }{ }^{(8)} \\
\text { lowa, EUA - } 1984\end{array}$ & $\begin{array}{l}\text { Estudo experimental } \\
\text { sobre os efeitos de vários } \\
\text { sistemas intravenosos } \\
\text { (dispositivo intravenoso } \\
\text { e bombas de infusão) } \\
\text { na integridade dos } \\
\text { glóbulos vermelhos; }\end{array}$ & $\begin{array}{l}\text { Bolsas armazenadas a } \\
5^{\circ} \mathrm{C} \text { foram deixadas a } \\
\text { temperatura ambiente } \\
\text { por duas horas para o } \\
\text { experimento. Coletadas } \\
\text { a mostras antes da } \\
\text { infusão para controle. } \\
\text { Coletada amostra de } \\
5 \text { ml de cada sistema } \\
\text { imediatamente após a } \\
\text { infusão para análises } \\
\text { das variáveis. }\end{array}$ & $\begin{array}{l}\text { A velocidade de infusão } \\
\text { ocasionou aumento da } \\
\text { hemólise proporcional } \\
\text { a o a u m e n to da } \\
\text { velocidade, sendo a } \\
\text { bomba peristáltica a } \\
\text { mais hemolítica em } \\
\text { velocidades menores. }\end{array}$ \\
\hline $\begin{array}{l}\text { Mateer, JR } \\
\text { Perry, BW } \\
\text { Tucker, JF } \\
\text { Aprahamian, C }{ }^{(9)} \\
\text { Wiscosin, EUA - } 1985\end{array}$ & $\begin{array}{l}\text { Estudo experimental } \\
\text { sobre efeito de cateter } \\
\text { intravenoso de grande } \\
\text { calibre, sobre hemólise } \\
\text { dos glóbulos vermelhos } \\
\text { segundo taxas de fluxo } \\
\text { máximas e aquecimento } \\
\text { do sangue. }\end{array}$ & $\begin{array}{l}\text { Bolsas de sangue } \\
\text { obsoletas ( } 37 \text { dias), com } \\
\text { hematócrito de } 45 \% \\
\text { foram submetidas a } \\
\text { compressões através } \\
\text { de um pressurizador } \\
\text { sendo geradas pressões } \\
\text { de } 300 \text { e } 600 \mathrm{mmHg} \\
\text { com vazão de } 100 \\
\text { ml/h. Amostras foram } \\
\text { coletadas após a } \\
\text { infusão para análises } \\
\text { das variáveis. }\end{array}$ & $\begin{array}{l}\text { O hemocomponente } \\
\text { instalado no dispositivo } \\
\text { in tra v e n o s o fo i } \\
\text { administrado segundo } \\
\text { as pressões empregadas, } \\
\text { porém o aquecimento } \\
\text { do sangue diminuiu } \\
\text { significativamente o } \\
\text { fluxo de infusão. } \\
\text { Não houve hemólise } \\
\text { significativa. }\end{array}$ \\
\hline $\begin{array}{l}\text { Thompson, HW } \\
\text { Lasky, LC } \\
\text { Polesky, HF (10) } \\
\text { Minnesota, EUA - } 1986\end{array}$ & $\begin{array}{l}\text { Estudo experimental } \\
\text { sobre a adequabilidade } \\
\text { d e b o m b a d e } \\
\text { infusão volumétrica } \\
\text { para transfusão de } \\
\text { concentrado de } \\
\text { hemácias. }\end{array}$ & $\begin{array}{l}\text { Bolsas com } 35 \text { dias } \\
\text { de armazenamento } \\
\text { foram infundidas com } \\
\text { velocidade de } 300 \text { a } 850 \\
\text { ml/h. Foram realizados } \\
\text { testes antes da infusão } \\
\text { para controle e após a } \\
\text { infusão para análise de } \\
\text { variáveis de interesse. }\end{array}$ & $\begin{array}{l}\text { A hemoglobina livre no } \\
\text { plasma aumentou após } \\
\text { a infusão de glóbulos, } \\
\text { porém não hou ve } \\
\text { hemólise significativa. }\end{array}$ \\
\hline
\end{tabular}




\begin{tabular}{|c|c|c|c|}
\hline $\begin{array}{l}\text { Burch, KJ } \\
\text { Phelps, SJ } \\
\text { Constance, TD(11) }\end{array}$ & $\begin{array}{l}\text { Estudo experimental } \\
\text { sobre o efeito da bomba } \\
\text { de infusão peristáltica } \\
\text { linear na integridade } \\
\text { dos concentrados de } \\
\text { hemácias e sangue total } \\
\text { durante a transfusão. }\end{array}$ & $\begin{array}{l}\text { Fo ram utilizadas } \\
\text { velocidades de infusão } \\
\text { de } 5 \text { a } 999 \mathrm{ml} / \mathrm{h} \text { com } \\
\text { hemácias frescas ( } 72 \\
\text { horas após doação) } \\
\text { e velhas ( } 72 \text { horas } \\
\text { após vencimento). O } \\
\text { sangue foi estocado } \\
\text { em temperatura de } 5^{\circ} \mathrm{C} \\
\text { até o dia do estudo e } \\
\text { no dia do experimento } \\
\text { foi deixado por duas } \\
\text { horas em temperatura } \\
\text { ambiente antes do uso. } \\
\text { Amostras pré e pós } \\
\text { infusão foram coletadas } \\
\text { para análise das variáveis. }\end{array}$ & $\begin{array}{l}\text { Não houve porcentagem } \\
\text { de hemólise significava } \\
\text { em todos os ensaios } \\
\text { realizados tanto com } \\
\text { hemácias frescas como } \\
\text { com hemácias velhas. }\end{array}$ \\
\hline $\begin{array}{l}\text { Hansen, TG } \\
\text { Sprogoe-Jacobse , U } \\
\text { Pedersen, C. M } \\
\text { Skovgaard Olsen, K } \\
\text { Risom Kristensen, S (12) } \\
\text { Escandinávia - } 1998\end{array}$ & $\begin{array}{l}\text { Estudo experimental } \\
\text { sobre o efeito de } \\
\text { diferentes bombas de } \\
\text { infusão na qualidade } \\
\text { dos glóbulos vermelhos } \\
\text { após transfusão. }\end{array}$ & $\begin{array}{l}\text { Foram utilizados } \\
\text { glóbulos com } 8 \text { a } 11 \\
\text { dias de armazenamento } \\
\text { e glóbulos com } 25 \text { a } 33 \\
\text { dias. } \\
\text { Foram utilizadas } \\
\text { bombas fluxométricas } \\
(6,9 \mathrm{ml} / \mathrm{s}) \text { e de seringa } \\
(300 \mathrm{mmHg}-2,9 \mathrm{ml} / \mathrm{s}) \text {. } \\
\text { A s bols as for a m } \\
\text { armazenadas a } 4{ }^{\circ} \mathrm{C} \\
\text { e infundidas em } 30 \\
\text { minutos aleatoriamente } \\
\text { por qualquer uma das } \\
\text { bombas. }\end{array}$ & $\begin{array}{l}\text { Glóbulos mais velhos } \\
\text { tiveram maior valor de } \\
\text { Hb livre, potássio livre } \\
\text { e LDH e apresentaram } \\
\text { hematócrito mais elevado. } \\
\text { Não houve diferenças } \\
\text { significativas na hemólise } \\
\text { segundo bombas de } \\
\text { infusão e tempo de } \\
\text { armazenamento dos } \\
\text { glóbulos. Glóbulos mais } \\
\text { novos apresentaram } \\
\text { pequeno aumento } \\
\text { da porcentagem de } \\
\text { hemólise e no LDH. }\end{array}$ \\
\hline $\begin{array}{l}\text { Frelich, R } \\
\text { Ellis, } \mathrm{MH}(13)\end{array}$ & $\begin{array}{l}\text { Estudo experimental } \\
\text { sobre o efeito do } \\
\text { pressurizador externo } \\
\text { e do diâmetro do } \\
\text { cateter sobre o grau de } \\
\text { hemólise de unidades } \\
\text { de glóbulos vermelhos. }\end{array}$ & $\begin{array}{l}\text { Foram utilizadas bolsas } \\
\text { de concentrados de } \\
\text { hemácias frescas }(\sim 10,8 \\
\text { dias) e velhas }(\sim 28,9 \\
\text { dias). Cada unidade foi } \\
\text { transfundida via cateteres } \\
\text { de calibres } 16 \mathrm{G}, 18 \mathrm{G}, \\
\text { 20Ge22Gecoletados os } \\
5 \text { ml finais da transfusão. } \\
\text { As transfusões em cada } \\
\text { cateter foram realizadas } \\
\text { sem o pressurizador } \\
\text { p n e u m á t i c o, } \\
\text { comparadas com o } \\
\text { uso de pressurizador } \\
\text { pneumático externo } \\
\text { com pressões de } 150 \\
\text { mmHg e } 300 \text { mmHg. }\end{array}$ & $\begin{array}{l}\text { O grau de hemólise } \\
\text { induzida por aplicação } \\
\text { de pressão externa } \\
\text { foi semelhante entre } \\
\text { unidades velhas e } \\
\text { frescas. O pressurizador } \\
\text { externo foi considerado } \\
\text { seguro na prática por } \\
\text { não causar hemólise } \\
\text { significativa. }\end{array}$ \\
\hline
\end{tabular}




\begin{tabular}{|c|c|c|c|}
\hline $\begin{array}{l}\text { Frey, B } \\
\text { Eber, S } \\
\text { Weiss, M (14) } \\
\text { Zurique, Suíça - } 2003\end{array}$ & $\begin{array}{l}\text { Estudo experimental } \\
\text { sobre o efeito de três } \\
\text { diferentes bombas de } \\
\text { infusão na integridade } \\
\text { dos glóbulos vermelhos. }\end{array}$ & $\begin{array}{l}\text { O armazenamento } \\
\text { das bolsas variou } \\
\text { de } 18 \text { a } 46,5 \text { dias. } \\
\text { As unidades foram } \\
\text { leucorreduzidas por } \\
\text { filtração, armazenados } \\
\text { a } 4^{\circ} \mathrm{C} \text { e deixadas em } \\
\text { temperatura ambiente } \\
\text { por uma hora antes do } \\
\text { experimento. Foram } \\
\text { testadas bombas de } \\
\text { seringa, peristáltica } \\
\text { c o n v e n c i o n a I e } \\
\text { v o l u m é tr i c a c o m } \\
\text { mecanismo shuttle. } \\
\text { Ofluxousadofoide20ml/h } \\
\text { e a duração da infusão foi } \\
\text { de } 2,5 h \text {. Os experimentos } \\
\text { foram repetidos em cada } \\
\text { bomba com oito diferentes } \\
\text { unidades de glóbulos. Na } \\
\text { parte final do equipo de } \\
\text { infusão das três bombas } \\
\text { foi conectado um cateter } \\
\text { calibre } 24 G \text { e foi simulada } \\
\text { uma pressão venosa de } 15 \\
\text { mmHga } 20 \text { cm acima das } \\
\text { bombas. }\end{array}$ & $\begin{array}{l}\text { Quantomaiorotempode } \\
\text { armazenamento maior } \\
\text { as concentrações de } \\
\text { potássio e hemoglobina } \\
\text { plasmáticos, fragilidade } \\
\text { osmótica e VCM. } \\
\text { Na análise de todos os } \\
\text { ensaios experimentais } \\
\text { com as três bombas de } \\
\text { infusão, a hemoglobina } \\
\text { do plasma, potássio, } \\
\text { LDH e bilirrubina } \\
\text { a u m e n t a } r \text { a m } \\
\text { significativamente após } \\
\text { a infusão. As bombas de } \\
\text { seringa e a peristáltica } \\
\text { apresentaram aumento } \\
\text { nas concentrações de } \\
\text { hemoglobina do plasma } \\
\text { e LDH comparadas a } \\
\text { bomba volumétrica. } \\
\text { Observou-se hemólise } \\
\text { significativa no estudo, } \\
\text { s e n d o a b om b a } \\
\text { volumétrica a menos } \\
\text { hemolítica. }\end{array}$ \\
\hline $\begin{array}{l}\text { Carvalho, EB } \\
\text { Borges, EL } \\
\text { Carlos, LMB } \\
\text { Silva, MAM } \\
\text { Magalhães, SMM } \\
\text { Gomes, FVBAF } \\
\text { Carvalho, MJC } \\
\text { Quixadá, ATS } \\
\text { Pitobeira, MHS }{ }^{(4)}\end{array}$ & $\begin{array}{l}\text { Estudo experimental } \\
\text { sobreograu dehemólise } \\
\text { de concentrados } \\
\text { de hemácias com } \\
\text { menos de } 10 \text { dias } \\
\text { de armazenamento } \\
\text { provocado por bombas } \\
\text { de infusão. }\end{array}$ & $\begin{array}{l}\text { Foram utilizadas uma } \\
\text { bomba de mecanismo } \\
\text { peristáltico rotatório } \\
\text { e duas de mecanismo } \\
\text { peristáltico linear de } \\
\text { marcas diferentes. } \\
\text { Foram testadas as } \\
\text { velocidades de infusão } \\
\text { de } 120 \mathrm{ml} / \mathrm{h}, 240 \mathrm{ml} / \mathrm{h} \\
\text { e } 360 \mathrm{ml} / \mathrm{h} \text {. Amostras } \\
\text { foram coletadas antes } \\
\text { da passagem pela } \\
\text { bomba de infusão, na } \\
\text { metade e no fim do } \\
\text { procedimento para } \\
\text { análise das variáveis. }\end{array}$ & $\begin{array}{l}\text { No presente estudo } \\
\text { observou-se que os } \\
\text { diferentes modelos e } \\
\text { mecanismos debombas } \\
\text { de infusão de soluções } \\
\text { (peristáltico linear e } \\
\text { peristáltico rotatório), } \\
\text { tempo e velocidades } \\
\text { ( V 1, V } 2 \text {, V3) não } \\
\text { provocaram alterações } \\
\text { signific ativas no s } \\
\text { parâmetros analisados } \\
\text { qu e e v i d e n c i a m } \\
\text { h e m ó I i s e n o s } \\
\text { c o n c e nt ra dos de } \\
\text { hemácias, ou seja, níveis } \\
\text { de hemoglobina livre e } \\
\text { potássio plasmático. }\end{array}$ \\
\hline
\end{tabular}




\begin{tabular}{|c|c|c|c|}
\hline $\begin{array}{l}\text { Parfitt, HS } \\
\text { Davies, SV } \\
\text { Tighe, P } \\
\text { Ewings, P (15) } \\
\text { Inglaterra - } 2007\end{array}$ & $\begin{array}{l}\text { Estudo experimental } \\
\text { sobre o dano em } \\
\text { glóbulos vermelhos } \\
\text { provocado por duas } \\
\text { bombas de infusão de } \\
\text { mecanismo peristáltico. }\end{array}$ & $\begin{array}{l}\text { Os experimentos foram } \\
\text { realizados com sangue } \\
\text { fresco(9dias), intermediário } \\
\text { (28 dias) e na data do } \\
\text { vencimento ( } 35 \text { dias). } \\
\text { O s a n g u e f o i } \\
\text { armazenado a } 4^{\circ} \mathrm{C} \text { e } \\
\text { foi utilizado em } 20 \\
\text { minutos após sair do } \\
\text { refrigerador. } \\
\text { As velocidades de } \\
\text { infusão foram: } 40 \text { ml/h } \\
\text { infundidas em } 4 \text { horas e } \\
150 \text { ml/h infundidos em } \\
2 \text { horas. Foram realizados } \\
\text { testes com dispositivo } \\
\text { gravitacional. As amostras } \\
\text { das duas bombas e a } \\
\text { gravitacional foram } \\
\text { recolhidas em tubos de } \\
\text { heparina e EDTA. }\end{array}$ & 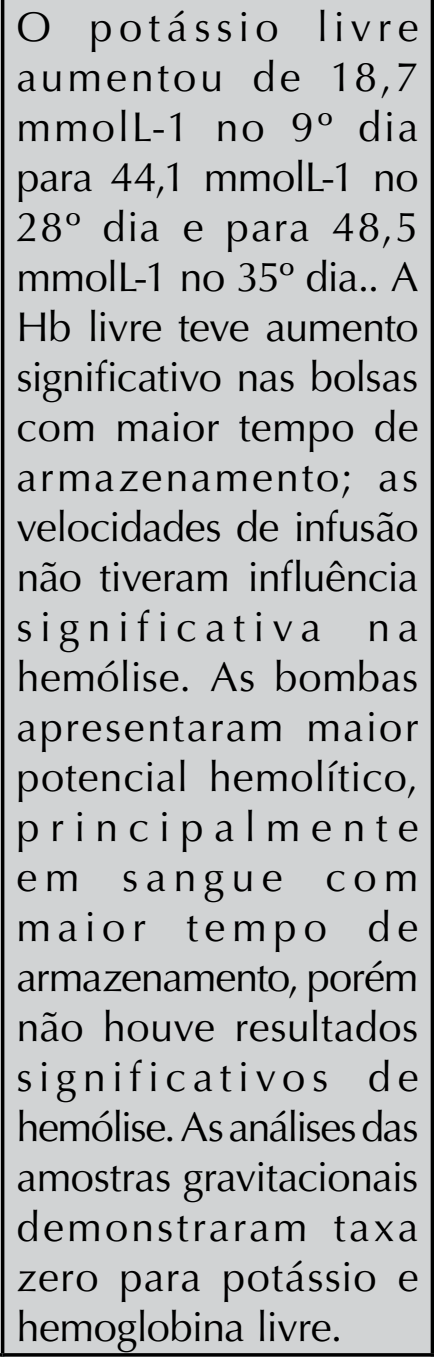 \\
\hline $\begin{array}{l}\text { Lieshout-Krikke, RW } \\
\text { Van der Meer, PF } \\
\text { Koopman, MMW } \\
\text { Korte, D (16) } \\
\text { Amsterdã, Holanda - } \\
2011\end{array}$ & $\begin{array}{l}\text { Estudo experimental } \\
\text { sobre a qualidade } \\
\text { in vitro de glóbulos } \\
\text { vermelhos após a } \\
\text { passagem por bomba } \\
\text { de infusão volumétrica } \\
\text { peristáltica. }\end{array}$ & $\begin{array}{l}\text { Foi realizado um teste } \\
\text { controle com infusão } \\
\text { gravitacional. As } \\
\text { velocidades de infusão } \\
\text { foram de } 100 \text { e } 300 \\
\text { ml/h. Os concentrados } \\
\text { de hemácias tinham } \\
30 \text { e } 35 \text { dias de } \\
\text { estocagem. Ao final } \\
\text { da linha de infusão foi } \\
\text { conectada uma bolsa } \\
\text { de transferência e as } \\
\text { amostras das duas } \\
\text { taxas de fluxo foram } \\
\text { coletadas in vitro para } \\
\text { medições. }\end{array}$ & $\begin{array}{l}\text { Nenhuma das bombas } \\
\text { de infusão induziu } \\
\text { aumento de Hb livre, } \\
\text { ligação de anexina } \\
\text { A } 5 \text { ou formação } \\
\text { de eritrócitos em } \\
\text { comparação com os } \\
\text { glóbulos das amostras } \\
\text { de controle. }\end{array}$ \\
\hline
\end{tabular}




\begin{tabular}{|c|c|c|c|}
\hline $\begin{array}{l}\text { Hod, EA } \\
\text { Brittenham, GM } \\
\text { Billote, GB } \\
\text { Francis, RO } \\
\text { Ginzburg,YZ } \\
\text { Hendrickson, JE } \\
\text { et al (17) } \\
\text { Nova Iorque, EUA - } \\
2011\end{array}$ & $\begin{array}{l}\text { Estudo experimental } \\
\text { sobre o efeito da } \\
\text { estocagem de unidades } \\
\text { de glóbulos vermelhos } \\
\text { no índice de hemólise } \\
\text { e a l ter a çõ es de } \\
\text { parâmetros sanguíneos. }\end{array}$ & $\begin{array}{l}\text { Foi realizada coleta por } \\
\text { aférese e transfusão } \\
\text { autóloga. Cada doador } \\
\text { foi transfundido após } 3 \\
\text { a } 7 \text { dias de estocagem } \\
\text { e após } 40 \text { a } 42 \text { dias } \\
\text { de estocagem. A } \\
\text { velocidade de infusão } \\
\text { foi de } 150 \mathrm{ml} / \mathrm{h} \text {. As } \\
\text { a m o st ra s fo ra m } \\
\text { coletadas } 90 \text { minutos } \\
\text { antes da transfusão, } \\
\text { imediatamente ao } \\
\text { início da transfusão e } \\
1,2,4,24 \text { e } 72 \text { horas } \\
\text { pós-transfusão. }\end{array}$ & $\begin{array}{l}\text { Hemólise extravascular: } \\
\text { comparado com a } \\
\text { transfusão de unidades } \\
\text { frescas, transfusões de } \\
\text { unidades velhas foram } \\
\text { associadas com aumento } \\
\text { significativo de bilirrubina } \\
\text { total no soro, com o pico } \\
\text { de aumento após quatro } \\
\text { horas datransfusão. Houve } \\
\text { aumento da hemoglobina } \\
\text { livre conforme o passar } \\
\text { do tempo. Não houve } \\
\text { diferença significativa } \\
\text { entre unidades frescas } \\
\text { e velhas nos níveis } \\
\text { de haptoglobina no } \\
\text { soro e LDH. Houve } \\
\text { aumento de ferro no } \\
\text { soro e na transferrina } \\
\text { nas unidades velhas. }\end{array}$ \\
\hline $\begin{array}{l}\text { Ley, JT } \\
\text { Yazer, MH } \\
\text { Waters, JH (18) } \\
\text { Pensilvânia, EUA - } 2012\end{array}$ & $\begin{array}{l}\text { Estudo experimental } \\
\text { cujo objetivo foi } \\
\text { avaliar e comparar } \\
\text { as características dos } \\
\text { glóbulos vermelhos } \\
\text { que são perdidos } \\
\text { e reinfundidos em } \\
\text { cirurgias de artroplastia } \\
\text { total de joelho, sendo } \\
\text { reprocessados por dois } \\
\text { dispositivos diferentes: } \\
\text { que executam lavagem } \\
\text { antes da reinfusão e } \\
\text { que não realizam a } \\
\text { lavagem. }\end{array}$ & $\begin{array}{l}\text { Os pacientes foram } \\
\text { divididos em dois } \\
\text { grupos, sendo que o } \\
\text { grupo } 1 \text { (grupo lavado) } \\
\text { foram operados por } \\
\text { cirurgiões que usam } \\
\text { o dispositivo que faz } \\
\text { lavagem de eritrócitos } \\
\text { e o grupo } 2 \text { (grupo não } \\
\text { lavado) foram operados } \\
\text { por cirurgiões que não } \\
\text { usam equipamentos } \\
\text { com lavag em de } \\
\text { eritrócitos. } \\
\text { Foram col et a das } \\
\text { amostras durante a } \\
\text { reinfusão do sangue } \\
\text { recuperado. As amostras } \\
\text { foram centrifugadas e o } \\
\text { sobrenadante avaliado. }\end{array}$ & $\begin{array}{l}\text { O grupo } 1 \text { apresentou } \\
\text { índice de hemoglobina } \\
\text { livre no plasma maior } \\
\text { que o grupo 2. A } \\
\text { diferença de índice de } \\
\text { hemólise entre os grupos } \\
\text { não foi estatisticamente } \\
\text { significante. O índice } \\
\text { de fragilidade da } \\
\text { membrana (MFI) foi } \\
\text { maior no grupo } 1 . \\
\text { Concluiu-se que o } \\
\text { grupo que utilizou a } \\
\text { lavagem de eritrócitos } \\
\text { a nte ri o rm e nte a } \\
\text { reinfusão apresentou } \\
\text { maior índice de Hb e } \\
\text { MFI, portanto maior } \\
\text { índice de hemólise. }\end{array}$ \\
\hline
\end{tabular}




\section{Número de Publicações por Ano}

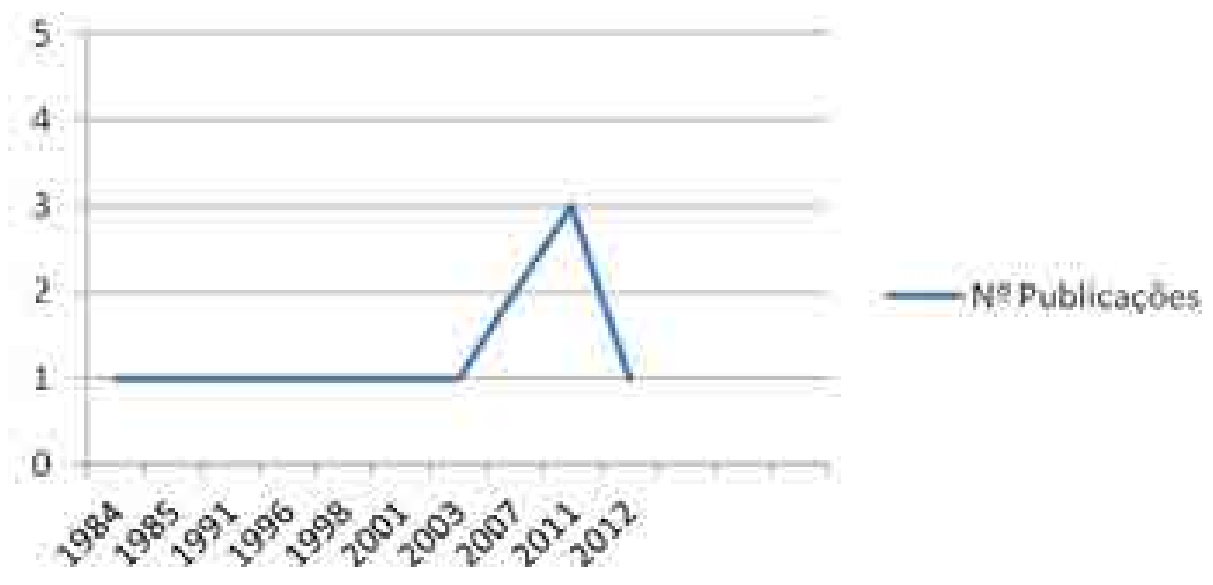

Figura 2 - Número de estudos disponíveis na literatura sobre manipulação e infusão de eritrócitos e hemólise, segundo ano de publicação.

Dos 12 artigos analisadosem sete(58,3\%) utilizaramse bombas de infusão, dois (16,6\%) abordaram procedimentos de manipulação de eritrócitos, um $(8,3 \%)$ testou dispositivos intravenosos e dois $(16,6 \%)$ estudaram a hemólise com as combinações de dispositivos. Para facilitar o entendimento os estudos foram separados em categorias. Abaixo serão citadas as categorias e os estudos inclusos em cada uma.

\section{Bombas de Infusão}

Os experimentos que avaliaram a relação entre hemólise e administração de hemocomponentes em bombas de infusão, foram realizados com bombas de infusão volumétrica e de seringa, com mecanismos peristáltico, linear ou rotatório, e velocidades de infusão que variaram de $5 \mathrm{ml} / \mathrm{h}$ a $999 \mathrm{ml} / \mathrm{h}$. Nestes estudos os concentrados de hemácias analisados tinham período de estocagem de 0 a 42 dias.

Dos sete estudos que avaliaram bombas de infusão, somente um (14,28\%) evidenciou hemólise nas bombas utilizadas, porém todos os estudos recomendam novos estudos e avaliações de novas bombas para recomendação de boas práticas.

\section{Dispositivos Intravenosos}

Um estudo analisou a aplicação de pressões de 300 e 600 mmHg em glóbulos vermelhos estocados a 37 dias em uma velocidade de infusão de $100 \mathrm{ml} / \mathrm{h}$. E ao avaliar hemólise em um cateter intravenoso de largo calibre, com altas velocidades de infusão e pressões não houve hemólise significativa em nenhuma das amostras estudadas. O estudo evidenciou que o único problema em aplicar altas taxas de fluxo e pressão no sangue, é que há aquecimento das células que acaba diminuindo o fluxo da infusão. Dos estudos com dispositivos intravenosos nenhum evidenciou altas taxas de hemólise.

\section{Combinação de Dispositivos}

Entre os 12 artigos selecionados, dois realizaram experimentos com combinações de dispositivos. O primeiro estudo apresentou que a bomba peristáltica causou mais hemólise que as demais e que a velocidade de infusão de 50 $\mathrm{ml} / \mathrm{h}$ apresentou maior grau de hemólise. Apesar de ser identificada hemólise em outro estudo, não houve valor significativo, ou maior que $1 \%$.

\section{Manipulação de Eritrócitos}

Nos dois estudos sobre manipulação de eritrócitos houve identificação de hemólise durante a manipulação. Entre as técnicas que ocasionaram hemólise destacaram-se a lavagem de glóbulos vermelhos e o armazenamento prolongado de glóbulos.

\section{Avaliação Geral dos Estudos}

Das 12 produções científicas selecionadas, $33,3 \%$ (quatro) tiveram resultado positivo para 
hemólise. Os equipamentos que causaram hemólise foram às bombas de infusão, e as técnicas empregadas no sangue que causaram hemólise foram: transfusão de sangue após lavagem de glóbulos e separação de hemocomponentes.

\section{DISCUSSÃO}

No que tange a ocorrência de hemólise, o primeiro problema de significado clínico relaciona-se ao aumento de hemoglobina livre que o sistema reticuloendotelial não consegue remover, causando hemoglobinemia com possíveis consequências ao sistema renal. Outro problema em potencial da hemólise é o excesso de potássio liberado para o meio extracelular, esse por sua vez, pode causar arritmias e em casos mais graves até a parada cardíaca e morte ${ }^{(19)}$.

Os estudos selecionados para essa revisão mostram que a hemólise ocorre nos processos de manipulação dos eritrócitos anteriores a transfusão (lavagem e armazenamento), e também na passagem por bombas de infusão e cateteres. Foi evidenciado que a hemólise não é dependente da velocidade de infusão, e sempre ocorreram conforme o aumento do armazenamento.

As unidades de hemocomponentes podem ser administradas por equipos próprios para infusão de sangue (possuem um filtro acoplado na câmara de gotejamento) e por bombas de infusão de vários tipos e mecanismos, que possuem sistemas de infusão de diferentes configurações. O regulamento técnico dos procedimentos hemoterápicos está definido na Portaria $n^{\circ}$ 2712/2013 que apresenta orientações sobre dispositivos e técnicas de infusão(20).

$\mathrm{Na}$ análise dos estudos pode-se afirmar que a bomba de infusão volumétrica foi a menos hemolítica, se comparada a de seringa e as fluxométricas com mecanismos peristálticos. Um problema em potencial, para classificação das bombas de infusão nos estudos, foi que cada um evidencia a bomba de infusão de uma forma, alguns estudos informam qual tipo de bomba de infusão estão analisando e outros apenas qual o mecanismo. Nos estudos de bombas de infusão, as com mecanismos peristáltico foram as mais hemolíticas, contudo não se evidencia adequada distinção entre as volumétricas e as fluxométricas.

Revisões integrativas da literatura tem por finalidade identificar evidências sobre determinada temática que se pretende estudar. Durante a análise dos estudos pode-se concluir que: não foram encontrados estudos publicados que tratem do efeito do equipo de micro e macrogotas sobre os glóbulos vermelhos durante uma transfusão sanguínea, este fato vem a fortalecer a importância do desenvolvimento de pesquisa para estes dispositivos. Em alguns estudos o equipo, ou a infusão gravitacional, é utilizada como controle para testes de outros equipamentos, porém não se tem o detalhamento dos resultados das análises feitas com esses dispositivos e não há descrição em literatura sobre seu real efeito sobre os glóbulos vermelhos ${ }^{(21)}$.

A segunda observação foi o número reduzido de publicações sobre o assunto, além de que os resultados na maioria das vezes são inconclusivos ou existe discordância entre os mesmos, assim até o momento não existem padrões definidos de equipamentos com segurança garantida, pois para tal é necessário maior número de estudos e com maior qualidade em suas metodologias.

A terceira constatação foi em relação aos tipos de estudos existentes, pode-se notar que a maioria dos estudos é relacionada a bombas de infusão e manipulação de eritrócitos, porém não há estudos sobre bombas de infusão fluxométrica, trazendo nova necessidade de pesquisa experimental para tais equipamentos.

\section{CONCLUSÕES}

Os estudos selecionados para essa revisão mostram que a hemólise ocorre nos processos de manipulação dos eritrócitos e também na passagem por bombas de infusão e cateteres. Foi evidenciado que a hemólise não é dependente da velocidade de infusão, e sempre ocorre conforme o aumento do tempo de armazenamento. Os estudos evidenciam que, dentre os diferentes tipos de bombas de infusão, a de infusão volumétrica causou menor nível de hemólise.

Em concordância com as conclusões de quase todos os estudos abordados, viu-se que dentro dessa linha de pesquisa ainda há muito que ser estudado e avaliado em termos de segurança em transfusão de concentrado de hemáceas por equipamentos gravitacionais ou automatizados. Certamente, os resultados apresentados poderão 
subsidiar novas pesquisas, para que sejam fundamentadas e pertinentes ao contexto da prática clínica, trazendo o conceito de segurança do paciente e melhora na prática assistencial dos enfermeiros.

\section{AGRADECIMENTOS}

Fundação de Amparo a Pesquisa do Estado de São Paulo edital no 2012/25284-9 e ao Conselho Nacional de Desenvolvimento Científico e Tecnológico edital n³03006/2012-9.

\section{REFERÊNCIAS}

1. Junqueira PC, Rosenblit J, Hamerschlak N. História da hemoterapia no Brasil. Rev Bras Hematol Hemoter. 2005;27(3):201-7.

2. Universidade Estadual de Campinas (UNICAMP). Hemocentro. Manual de orientações em hemoterapia. Campinas, 2008.

3. Souza MH, Elias DO. Fundamentos da Circulação Extra Corpórea. $2^{a}$ edição. Centro Editorial Alfa Rio: Rio de Janeiro, 2006.

4. Carvalho EB, Borges EL, Carlos LMB, Silva MAM, Magalhães SMM, Gomes FVBAF, et al. Efeito da bomba de infusão de soluções sobre o grau de hemólise em concentrado de hemácias. Rev Bras Hematol Hemoter 2007;29(2):149-52.

5. Conselho Federal de Enfermagem . Resolução $n^{\circ}$ 306/2006. Normatiza a atuação do enfermeiro em hemoterapia. Rio de Janeiro: COFEN; 2006.

6. Harada MJCS, Pedreira MLG. Terapia intravenosa e infusões. $1^{\text {a }}$ edição. Yendis Editora: São Caetano do Sul, 2011.

7. Mendes KDS, Silveira RCCP, Galvão CM. Revisão integrativa: método de pesquisa para a incorporação de evidências na saúde e na enfermagem. Texto \& contexto enferm. 2008;17(4):758-64.

8. Gibson JS, Leff RD, Roberts RJ. Effects of intravenous delivery systems on infused red blood cells. Am J Hosp Pharm. 1984;41(3):468-72

9. Mateer JR, Perry BW, Tucker JF, Aprahamian C. Effects of rapid infusion with high pressure and large-bore iv tubing on red blood cell lysis and warming. Ann Emerg Med. 1985;10(14):966-9.

10. Thompson HW, Lasky LC, Polesky HF. Evaluation of a volumetric intravenous fluid infusion pump for transfusion of blood components containing red cells. Transfusion. 1986;26(3):290-3

11. Burch KJ, Phelps SJ, Constance TD. Effect of an infusion device on the integrity of whole blood and packed blood cells. Am J Hosp Pharm. 1991;48(1):92-6.

12. Hansen TG, Sprogoe-Jacobse U, Pedersen CM, Skovgaard Olsen K, Kristensen SR. Haemolysis following rapid experimental red blood cell transfusion--an evaluation of two infusion pumps. Acta Anaesfhesiol Scand 1998;42(1):57-62

13. Frelich $\mathrm{R}$, Ellis $\mathrm{MH}$. The effect of external pressure, catheter gauge, and storage time on hemolysis in RBC transfusion. Transfusion. 2001;41(6):799-802.

14. Frey B, Eber S, Weiss M. Changes in red blood cell integrity related to infusion pumps: a comparison of three different pump mechanisms. Pediatr Crit Care Med. 2003;4(4):465-70.

15. Parfitt HS, Davies SV, Tighe P, Ewings P. Red cell damage after pumping by two infusion control devices (Arcomed VP 7000 and IVAC 572). Transfus Med. 2007;17(4):290-5.

16. Lieshout-Krikke RW, Van der Meer PF, Koopman MMW, Korte D. Effect on the quality of blood components after simulated blood transfusions using volumetric infusion pumps. Transfusion. 2011;51(8):1835-9.

17. Hod EA, Brittenham GM, Billote GB, Francis RO, Ginzburg YZ, Hendrickson JE, et al. Transfusion of human volunteers with older, stored red blood cells produces extravascular hemolysis and circulating nontransferrin-bound iron. Blood. 2011;118(25):6675-82.

18. Ley JT, Yazer MH, Waters JH. Hemolysis and red blood cell mechanical fragility in shed blood after total knee arthroplasty. Tranfusion 2012;52(1):34-8.

19. Sowemimo-Coker, SO. Red blood cell hemolysis during processing. Transfus Med Rev.2002;16(1):46-60

20. Ministério da Saúde (BR). Portaria $\mathrm{n}^{\circ}$ 2.712, de 12 novembro de 2013. Redefine o regulamento técnico de procedimentos hemoterápicos. Diário Oficial da União, [Internet] 12 nov 2013. [acesso em 23 fev 2015]. Disponível: http://bvsms.saude.gov.br/bvs/saudelegis/ gm/2013/prt2712_12_11_2013.html

21. Pedreira MLG. Uso de bombas de infusão na terapia intravenosa em crianças assistidas em unidades de cuidados intensivos pediátricos: contribuições para estudos. [tese]. São Paulo (SP): Universidade Federal de São Paulo; 1999. 